\title{
Economix
}

http://economix.fr

Document de Travail Working Paper 2014-51

Open Access vs. Restricted Access with Two Variable Factors: On the Redistributive Effects of a Property Regime Change

Ronan Congar Louis Hotte

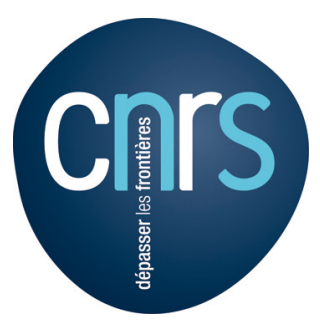

UMR 7235
Université de Paris Ouest Nanterre La Défense (bâtiment G)

200, Avenue de la République 92001 NANTERRE CEDEX

Tél et Fax : 33.(0)1.40.97.59.07 Email : nasam.zaroualete@u-paris10.fr université

Paris Ouest

Nanterre La Défense 


\title{
Open Access vs. Restricted Access with Two Variable Factors: On the Redistributive Effects of a Property Regime Change ${ }^{1}$
}

\author{
Ronan Congar $^{2} \quad$ Louis Hotte ${ }^{3}$ \\ Working Paper \\ This version: August, 2014
}

\footnotetext{
${ }^{1}$ This paper has benefited from comments by Stefan Ambec, Victoria Barham, Brian Copeland and seminar participants at the University of Ottawa, Université de Rouen, the 2012 CREE Meetings at UBC, the 2012 Conference on Environment and Natural Resources Management in Developing and Transition Economies at Université d'Auvergne, the 2014 Montreal Natural Resources and Environmental Economics Workshop at Mcgill University and Economix - Université Paris Ouest Nanterre La Défense.

${ }^{2}$ EconomiX, UMR CNRS 7235 Université Paris Ouest - Nanterre La Défense and Economics Department, University of Ottawa (ronan.congar@gmail.com).

${ }^{3}$ Economics Department, University of Ottawa (louis.hotte@uottawa.ca).
} 


\section{Abstract \\ Open Access vs. Restricted Access with Two Variable Factors: On the Redistributive Effects of a Property Regime Change}

We consider the factor payment effects of a transition from open access to restricted access in the resource sector in the long-run, i.e., when both labor and capital are mobile between sectors. We show that the transition benefits (harms) the factor that is initially used more (less) intensively in the manufacturing sector relative to the resource sector. Our analysis introduces a dual approach used to compare equilibria between property regime types.

Keywords: Property Rights, Natural Resources, Mobile Capital, Factor Payments, Income Distribution, Dual Approach.

JEL classification: D02, D23, D33, K11, Q2, N5, O13.

\section{Libre accès et accès contrôlé avec deux facteurs variables: Une analyse des effets redistributifs d'un changement de régime de propriété}

Nous analysons l'impact de long terme sur les revenus des facteurs produit par une transition du régime de propriété dans le secteur des ressources naturelles, soit du libre-accès vers l'accès contrôlé. Par long terme, nous entendons le fait que le capital soit mobile entre les secteurs au même titre que la main d'oeuvre. Nous montrons que la transition avantage le (nuit au) facteur qui est initiallement utilisé de manière plus (moins) intensive dans le secteur manufacturier relativement au secteur de la ressource. Notre analyse introduit l'approche duale afin de comparer les régimes de propriété en équilibre général.

Mots clefs: Droits de propriété, ressources naturelles, mobilité du capital, revenus des facteurs, distribution du revenu, approche duale. 


\section{Introduction}

A central result in the literature on property right economics holds that in a general equilibrium setting, the privatization of the natural resource sector, though efficient, will lead to lower labor wages. This result is attributed to Weitzman (1974) and Samuelson (1974), who more generally show that restricting access in the use of a fixed factor (e.g. natural resources or agricultural land) makes the variable factor (e.g. labor) worse off as compared to a situation of open access to the fixed factor. In this paper, we reconsider the general-equilibrium redistributive effects of a property regime change from open access to restricted access in the resource sector. We show in particular that with the addition of a second variable factor (e.g. physical capital), labor may gain from resource privatization.

To see why, imagine an economy with two sectors: manufacturing and (natural) resource. The resource sector is initially exploited under open access. ${ }^{1}$ While restricting access in the resource sector may drive out labor, it will also drive out capital. As both factors move into the manufacturing sector in (generally) unequal proportions, factor intensities are affected and consequently, factor returns change in opposite directions. Our principal result states that labor gains from resource privatization if, and only if, the manufacturing sector is labor intensive relative to the resource sector under open access.

The problem is reminiscent of the difference between the specific-factor and the Heckscher-Ohlin models of trade. ${ }^{2}$ The specific-factor model assumes that only labor can move between sectors while capital is riveted to its sector; as such, its implications are viewed as delivering the short-run, factor-income effects of trade. Given that the analyses by Weitzman and Samuelson are based on the same assumption, one may similarly view their results as the short-run effects of a property regime change. The Heckscher-Ohlin model takes a longer term view by assuming that both labor and capital can freely move between sectors. By analogy, our results may be viewed as the long-run,

\footnotetext{
${ }^{1}$ Note that in this text, an open access regime refers to the absence of exclusion or restrictions in the use of natural resources. This contrasts with a restricted access regime, which refers to a situation where some entity enjoys full property rights over a resource in such manner that it can control access perfectly and at no cost. Restricted access therefore includes: private property when the entity is an individual or a firm; common property when it is a local collective; and public property when it is the state.

${ }^{2}$ See Jones (1971), Mayer (1974) and Mussa (1974).
} 
factor income effects of a property regime change.

This paper includes further contributions. One consists in the use of a dual approach to equilibrium in the production sector used to analyze a property regime change; to our knowledge, this had not been done before. Another is the derivation of the conditions used to characterize an open access equilibrium in the presence of multiple mobile factors of production. We also show that even though resource privatization leads to a drop in the price of one factor and an increase in the price of the other, the net effect is such that the resource is exploited less intensively under restricted access through a reduced use of both factors.

The Weitzman-Samuelson proposition sparked a literature which extended the model's basic assumptions into various applications. Anderson and Hill (1983) argue that privatization may not be more efficient if it leads to competing claims to ownership that uses up real resources. Brooks and Heijdra (1990) show that labor wages may increase following privatization if extra labor is required to enforce private property. Brito, Intriligator and Sheshinski (1997) consider a heterogeneous labor force and also show that the wage could increase following privatization. Baland and Francois (2005) argue that open access to a resource may act as an insurance mechanism and thus be ex-ante Pareto superior to private ownership. Ambec and Hotte (2006) show that when workers have heterogeneous productivities, private property may benefit the less productive when enforcement is imperfect. While all of these papers provide interesting qualifications to the Weitzman-Samuelson proposition, all assume labor to be the only variable factor. Though this may seem a fair assumption to make for the short run, a long run view should include capital as a second variable factor.

To our knowledge, de Meza and Gould (1987) is the only paper that mentions the potentially important role of a second variable factor; they did not, however, provide a general-equilibrium analysis. We propose a model which uncovers the precise mechanisms at work and provides necessary and sufficient conditions under which wages increase following privatization.

This paper was also inspired by Karp (2005), who argues that when considering the interactions between trade openness, property regimes, and natural resource use, one should treat both labor and capital as mobile factors between the resource and manufacturing sectors. This was in response to previous analysis that ignored the role of capital, such as Chichilnisky (1994), Brander and Taylor (1997) and Hotte, Long and Tian (2000). But while Karp (2005) analyzes the link between trade openness and the excludability 
of capital use, we consider the redistributive effects of a change in property regime for a small open economy with perfectly excludable capital throughout.

The paper is organised as follows. In Section 2, the economy is defined with production technologies and resource endowments. Sectoral equilibrium conditions are laid out in Section 3 for the cases of both open access and restricted access. The general equilibrium analysis appears in Section 4. The conclusion discusses some implications for empirical work as well as possible extensions.

\section{The production technologies}

The economy is composed of two sectors: a manufacturing sector $(M)$ and a (natural) resource sector $(R)$.

\subsection{The manufacturing sector}

Manufactures are produced using two types of factors, labor $x_{l}^{M}$ and capital $x_{k}^{M}$, with a constant returns to scale technology. The output $y^{M}$ of the entire manufacturing sector can thus be represented by the following relation:

$$
y^{M}=F^{M}\left(\mathbf{x}^{M}\right),
$$

where $\mathbf{x}^{M}$ is input vector $\left(x_{l}^{M}, x_{k}^{M}\right)$ and $F^{M}$ is a function which is twice continuously differentiable, strictly quasi-concave, homogeneous of degree one, increasing in both arguments and such that $F^{M}(\mathbf{0})=0$.

\subsection{The resource sector}

To simplify, the resource sector is composed of one resource site of size $Q$. We abstract from stock-flow resource dynamics by assuming that $Q$ is fixed. In order to produce resource goods, three input types are required: labor $x_{l}^{R}$, capital $x_{k}^{R}$ and a resource site of size $Q$. The resource production technology exhibits constant returns to scale in the three-input vector $\left(x_{l}^{R}, x_{k}^{R}, Q\right)$. However, since $Q$ is fixed by nature, then production in the resource sector really exhibits decreasing returns to scale with respect to variable input vector $\mathbf{x}^{R} \equiv\left(x_{l}^{R}, x_{k}^{R}\right)$. Since the size of input $Q$ is fixed throughout, it is dropped from the notation so that the resource output is simply represented as a function of the two variable inputs. 
The resource production function is assumed homothetic with respect to $\mathbf{x}^{R}$, i.e. $y^{R}=f\left(F^{R}\left(\mathbf{x}^{R}\right)\right)$, with function $f$ assumed twice continuously differentiable, increasing, strictly concave and such that $f(0)=0$, and function $F^{R}$ is assumed twice continuously differentiable, strictly quasi-concave, homogeneous of degree one, increasing in both arguments and such that $F^{R}(\mathbf{0})=0$. The effective effort exerted at exploiting the resource is therefore defined as $z=F^{R}\left(\mathrm{x}^{R}\right)$. To summarize, we have:

$$
\begin{gathered}
y^{R}=f(z), \quad[\text { resource output }] \\
z=F^{R}\left(\mathbf{x}^{R}\right) .[\text { resource exploitation effort }]
\end{gathered}
$$

The economy's total endowments in the mobile factors are denoted $\bar{x}_{i}$, $i \in\{l, k\}$. The following input market clearing conditions must therefore be respected:

$$
x_{i}^{M}+x_{i}^{R}=\bar{x}_{i}, \quad i \in\{l, k\} .
$$

\section{Equilibrium conditions}

As mentioned in the previous section, there are three input types in this economy: labor, capital, and a resource site. The first two, labor and capital, are perfectly excludable at no cost. In the case of the resource site, we shall consider two polar cases of property regimes, following Weitzman (1974) and Samuelson (1974):

Restricted access (RA) Exclusion is performed by the owner(s) of the resource site, perfectly and costlessly.

Open access (OA) The resource site can be accessed by anyone without any restriction whatsoever.

Note that in the case of the RA equilibrium, it is irrelevant to determine who owns the site; all that matters is that owners seek to maximize rents by hiring the right combination of variable inputs, and exclude others. Exclusion can just as well be performed by one firm or by a local community as common property owners.

We take manufactures as the numéraire good. $w_{i}$ denotes the respective factor prices. $p$ is the price of the resource good. As a simplification, we consider only the case of a small open economy in which $p$ is fixed on world markets. In the case of the endogenous factor prices, we assume price taking 
behavior by producers throughout and consider only interior solutions in which both sectors are simultaneously active.

\subsection{Manufacturing sector}

In order to maximize profits, manufacturers simply equate marginal product values with factor prices, i.e., ${ }^{3}$

$$
F_{i}^{M}\left(\mathbf{x}^{M}\right)=w_{i}, \quad i \in\{l, k\} .
$$

In order to represent the equilibrium in the manufacturing sector, it will also be convenient to make use of the cost-minimization dual to (5). Given constant-returns to scale, the unit cost of producing one unit of manufacturing output depends on factor prices only and is denoted $c^{M}(\mathbf{w})$; this function has the usual properties of a cost function. Since manufactured goods are used as numéraire goods, the equilibrium in the manufacturing sector is represented by the following zero-profit condition:

$$
c^{M}(\mathbf{w})=1
$$

\subsection{Resource sector}

Equilibrium conditions in the resource sector depend on which property regime prevails.

\subsubsection{Restricted access}

Under RA, the resource owner gets to choose variable input vector $\left(x_{l}^{R}, x_{k}^{R}\right)$ by hiring labor and capital in order to maximize profits. The problem of the firm is

$$
\max _{\mathbf{x}^{R}} \pi=p f(z)-\mathbf{x}^{R} \mathbf{w}^{\prime},
$$

where $z=F^{R}\left(\mathbf{x}^{R}\right)$ and $\mathbf{w}^{\prime}$ is the transpose of input price vector $\mathbf{w} \equiv\left(w_{l}, w_{k}\right)$. This yields the following pair of first-order conditions:

$$
p f^{\prime}(z) F_{i}^{R}\left(\mathbf{x}^{R}\right)=w_{i}, \quad i \in\{k, l\} .
$$

This condition simply states that under exclusive access, the owner equates the marginal product value of each variable factor to its cost.

\footnotetext{
${ }^{3}$ The subscript of a function denotes a partial derivative.
} 
When comparing property regimes, it will be useful to look at the problem from the perspective of cost minimization. As a profit maximizer, the owner seeks to minimize the cost of any realized exploitation effort level $z$. Now given that $z=F^{R}\left(\mathbf{x}^{R}\right)$, that $F^{R}$ exhibits constant returns to scale, and price taking, the unit cost of $z$ is considered constant by the resource owner and dependent on input vector cost $\left(w_{l}, w_{k}\right)$. As a result, letting $c^{R}(\mathbf{w})$ denote the unit cost of $z$, the problem of the owner can also be expressed as follows:

$$
\max _{z} \pi=p f(z)-z c^{R}(\mathbf{w})
$$

The optimal exploitation effort is thus given by

$$
p f^{\prime}(z)=c^{R}(\mathbf{w}) \text {. }
$$

Conditions (8) and (10) are equivalent ways to represent the RA exploitation level on a resource site.

\subsubsection{Open access}

In the spirit of Gordon (1954), open access leads to a complete dissipation of rents on a resource site. Looking at this from the perspective of the choice of effective effort level $z$ with unit $\operatorname{cost} c^{R}(\mathbf{w})$, the open-access analog to condition (10) is the following: ${ }^{4}$

$$
p \phi(z)=c^{R}(\mathbf{w})
$$

where $\phi(z) \equiv f(z) / z$ denotes the average product of effective effort. In order to arrive at the main result of this paper, however, we make use of the following proposition, which represents the open-access analog to condition (8):

Proposition 1 In the presence of two variable inputs, open access is characterized by the following equilibrium conditions, which correspond to rent dissipation:

$$
p \phi(z) F_{i}^{R}\left(\mathbf{x}^{R}\right)=w_{i}, \quad i \in\{k, l\} .
$$

\footnotetext{
${ }^{4}$ As noted in Cheung (1970), rent dissipation would not be complete under free access with a limited number of users. In this respect, our open access equilibrium approximates a situation with a large number of users.
} 
Proof: Let $x_{i}(\mathbf{w})$ denote the conditional demand for factor $i$ required to exert one unit of effective effort $z$. Rent dissipation and cost minimization respectively require: $c^{R}(\mathbf{w})=w_{k} x_{k}(\mathbf{w})+w_{l} x_{l}(\mathbf{w})$ and $F_{k}^{R} / F_{l}^{R}=w_{k} / w_{l}$. Moreover, since $F^{R}\left(\mathbf{x}^{R}\right)$ is homogeneous of degree 1 , we have $F^{R}\left(\mathbf{x}^{R}\right)=x_{k} F_{k}^{R}+x_{l} F_{l}^{R}$. With a bit of simple algebra, substitution of the last two equalities into the previous expression for $c^{R}(\mathbf{w})$ yields $c^{R}(\mathbf{w})=w_{i} / F_{i}^{R}$ for $i \in\{k, l\}$. Substitute then into condition (11) to obtain expression (12). Q.E.D.

Note that conditions (12) subsume two properties of the OA equilibrium: one is a cost minimizing factor combination to achieve effort level $z$ (this is also present in (8)); another is rent dissipation (this differs from (8)). Taking the case of capital to illustrate, condition (12) can be interpreted as follows. Adding one more unit of capital will increase the effective effort by $F_{k}$. This increase is then multiplied by the average product of effective effort in order to arrive at the extra output received by one user; this increase exceeds the overall increase because it ignores the cost imposed on other users in terms of reduced average product of effective effort ${ }^{5}$. The only cost that each user accounts for is the direct cost of capital $w_{k}$. This contrasts with RA condition (8), where multiplication with the marginal product of effective effort indicates that the drop in average product of all users is well accounted for.

Under RA, the economy's general equilibrium is characterized by the following set of nine equations: (1), (2), (3), (4), (5) and (8). It contains nine endogenous variables: $\mathbf{w}, \mathbf{x}^{M}, \mathbf{x}^{R}, z, y^{M}$ and $y^{R}$. In the next section, we will use "circumflex" superscript " to denote the equilibrium values of variables under exclusive access.

The general equilibrium under $\mathrm{OA}$ is characterized by the following set of nine equations: (1), (2), (3), (4), (5) and (12). Compared to RA, only condition (8) has been replaced by (12). We will use "tilde" superscript ${ }^{\sim}$ to denote the equilibrium values of variables under OA.

\section{Results}

Our main result is presented in Section 4.1 in the form of Theorem 1. For expository purposes, in order to demonstrate Theorem 1 in Section 4.1, we

\footnotetext{
${ }^{5}$ Note that this assumes the presence of an arbitrarily large number of users (Cheung, 1970).
} 
impose a priori that the resource sector's effective effort level under RA is lower than under OA, i.e., $\hat{z}<\tilde{z}$. The demonstration that this inequality must hold is presented in Section 4.2.

\subsection{Factor payment effects}

Let us define factor intensity as follows:

Definition Let $\xi_{i}\left(\mathbf{x}^{S}\right) \equiv x_{i}^{S} / x_{j}^{S}, i, j \in\{l, k\}, i \neq j$, denote factor $i$ 's intensity of use in sector $S, S \in\{M, R\}$.

Theorem $1 \quad \hat{w}_{i} \geq \tilde{w}_{i} \Leftrightarrow \xi_{i}\left(\tilde{\mathbf{x}}^{M}\right) \geq \xi_{i}\left(\tilde{\mathbf{x}}^{R}\right)$.

Theorem 1 states that restricting access will benefit (harm) the factor that is used more (less) intensively in the manufacturing sector relative to the resource sector under open access. In order to demonstrate this theorem, let us introduce some lemmas.

Lemma 1 states that both sector's factor intensities vary in the same direction when access is restricted.

Lemma $1 \xi_{i}\left(\tilde{\mathbf{x}}^{M}\right) \leq \xi_{i}\left(\hat{\mathbf{x}}^{M}\right) \Leftrightarrow \xi_{i}\left(\tilde{\mathbf{x}}^{R}\right) \leq \xi_{i}\left(\hat{\mathbf{x}}^{R}\right)$

Proof: Regardless of the prevailing property regime, cost minimization in the production of manufactures and resource exploitation effort requires the following condition to hold:

$$
\frac{F_{i}^{M}}{F_{j}^{M}}=\frac{w_{i}}{w_{j}}=\frac{F_{i}^{R}}{F_{j}^{R}} .
$$

Now marginal products $F_{i}^{M}$ and $F_{j}^{M}$ are respectively decreasing and increasing in factor $i$ 's intensity. Hence if the factor price ratio $w_{i} / w_{j}$ decreases (increases), factor $i$ 's intensity must be increasing (decreasing) in both sectors. Q.E.D.

Lemma 1 can be illustrated with the help of Figure 1. Here, $O^{R}$ and $O^{M}$ denote the origins for the resource and manufacturing sectors respectively, and $\bar{x}_{i}$ and $\bar{x}_{j}$ are the economy's total factor endowments. One notes that the manufacturing sector is relatively factor- $i$ (factor- $j$ ) intensive for all factor allocations above (below) the diagonal line $O^{R} O^{M}$. Lemma 1 therefore 
implies that if the manufacturing sector is relatively factor- $i$ (factor- $j$ ) intensive under OA, as with the point labeled $\tilde{\mathbf{x}}\left(\tilde{\mathbf{x}}^{\prime}\right)$, then the RA equilibrium must fall in either of areas $A$ or $B\left(A^{\prime}\right.$ or $\left.B^{\prime}\right)$. One consequence is that the sectors retain their relative factor intensities after the regime change. Hence the following corollary:

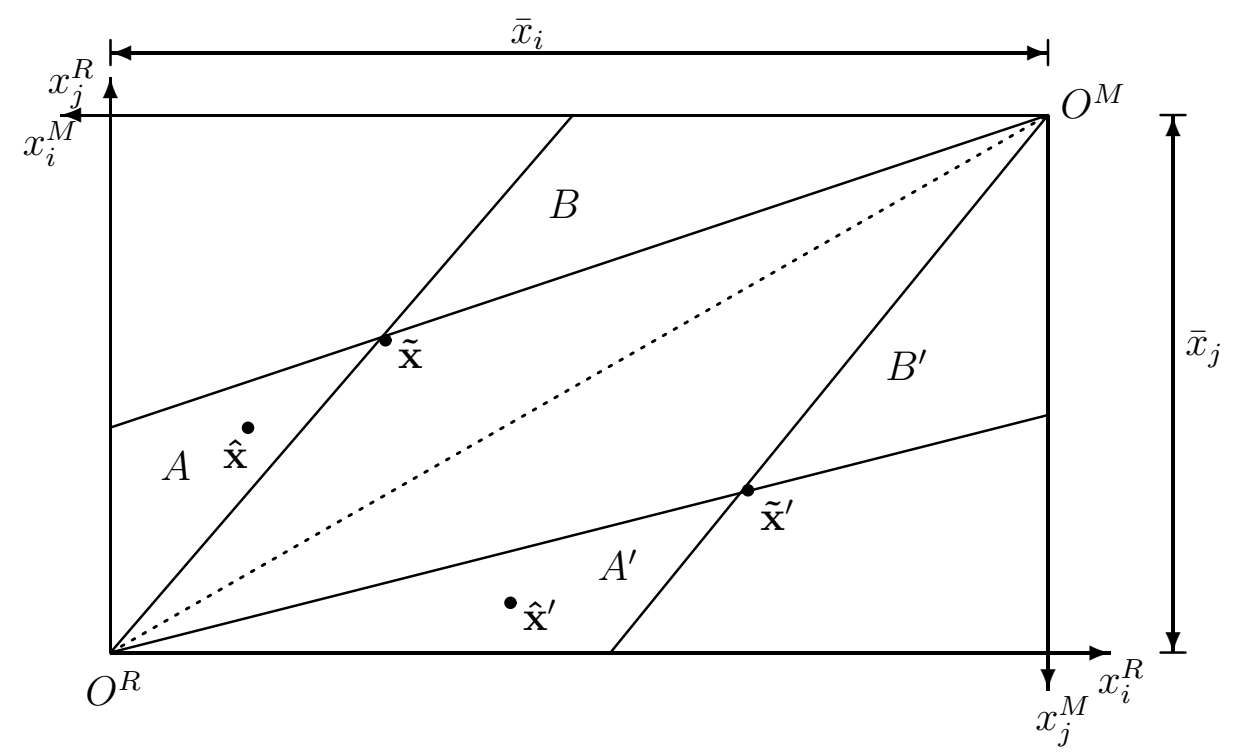

Figure 1: Property regimes, factor allocations, and factor intensities

Corollary 1 There is no factor intensity reversal (FIR) associated with a property regime change.

Proof: A reversal of relative factor intensities between sectors implies that equilibria in each property regime are located on opposite sides of the diagonal line $O^{R} O^{M}$ in Figure 1. This violates Lemma 1. Q.E.D.

The following lemma states that when RA is consistent with a drop in resource use efforts as compared to OA, then RA leads to a decreased use of both factors in the resource sector. (Note that Lemma 2 does not demonstrate that effective input efforts in the resource sector decrease under RA. This demonstration is relegated to Section 4.2.) 
Lemma $2 \hat{z}<\tilde{z} \Leftrightarrow \hat{\mathbf{x}}^{R} \ll \tilde{\mathbf{x}}^{R}$ (and equivalently $\hat{\mathbf{x}}^{M} \gg \tilde{\mathbf{x}}^{M}$ ).

Proof: i) $\Rightarrow$ Given that $\hat{z}<\tilde{z}$, then either $\hat{x}_{k}^{R}<\tilde{x}_{k}^{R}$ or $\hat{x}_{l}^{R}<\tilde{x}_{l}^{R}$, or both. However, if one factor increases while the other decreases in the resource sector, market clearing implies that the opposite happens in the manufacturing sector, which means that factor intensities move in opposite directions, thus violating Lemma 1 . Consequently, it must be the case that $\hat{x}_{k}^{R}<\tilde{x}_{k}^{R}$ and $\hat{x}_{l}^{R}<\tilde{x}_{l}^{R}$, and as a result of market clearing, we have $\hat{x}_{k}^{M}>\tilde{x}_{k}^{M}$ and $\hat{x}_{l}^{M}>\tilde{x}_{l}^{M}$.

ii) $\Leftarrow$ is obvious. Q.E.D.

The following lemma states that if, under OA, the manufacturing sector uses factor $i$ more intensively than the resource sector, then the intensity of use of factor $i$ must be lower under RA, and conversely.

Lemma 3 If $\hat{z}<\tilde{z}$ then $\xi_{i}\left(\tilde{\mathbf{x}}^{M}\right) \geq \xi_{i}\left(\tilde{\mathbf{x}}^{R}\right) \Leftrightarrow \xi_{i}\left(\tilde{\mathbf{x}}^{M}\right) \geq \xi_{i}\left(\hat{\mathbf{x}}^{M}\right)$.

Proof: i) $\Rightarrow$ According to Lemma 1, given that $\xi_{i}\left(\tilde{\mathbf{x}}^{M}\right) \geq \xi_{i}\left(\tilde{\mathbf{x}}^{R}\right)$, as depicted by point $\tilde{\mathbf{x}}$ in Figure 1, the new equilibrium with RA must fall strictly within either of areas $A$ or $B$. Lemma 2 , however, rules out area $B$ as a possibility when $\hat{z}<\tilde{z}$. As a result, the RA equilibrium is such that $\xi_{i}\left(\tilde{\mathbf{x}}^{M}\right) \geq \xi_{i}\left(\hat{\mathbf{x}}^{M}\right)$.

ii $\Leftarrow$ a) Begin with the strict inequality $\xi_{i}\left(\tilde{\mathbf{x}}^{M}\right)>\xi_{i}\left(\hat{\mathbf{x}}^{M}\right)$. According to Lemma 1 , we also have $\xi_{i}\left(\tilde{\mathbf{x}}^{R}\right)>\xi_{i}\left(\hat{\mathbf{x}}^{R}\right)$. It is straightforward to verify then that when $\xi_{i}\left(\tilde{\mathbf{x}}^{M}\right)<\xi_{i}\left(\tilde{\mathbf{x}}^{R}\right)$, the preceding two inequalities imply $\hat{z}>\tilde{z}$, which we ruled out.

b) In the case of a strict equality $\xi_{i}\left(\tilde{\mathbf{x}}^{M}\right)=\xi_{i}\left(\hat{\mathbf{x}}^{M}\right)$, Lemma 1 implies $\xi_{i}\left(\tilde{\mathbf{x}}^{R}\right)=\xi_{i}\left(\hat{\mathbf{x}}^{R}\right)$. Therefore $F_{i}^{M}\left(\tilde{\mathbf{x}}^{M}\right)=F_{i}^{M}\left(\hat{\mathbf{x}}^{M}\right)$ and $F_{i}^{R}\left(\tilde{\mathbf{x}}^{R}\right)=F_{i}^{R}\left(\hat{\mathbf{x}}^{R}\right)$. From (5), (8) and (12) this implies that $p f^{\prime}(\hat{z})=p \phi(\tilde{z})$ and thus $\hat{z}<\tilde{z}$. Suppose now that $\xi_{i}\left(\tilde{\mathbf{x}}^{M}\right)<\xi_{i}\left(\tilde{\mathbf{x}}^{R}\right)$. It is straightforward to verify then that equal factor intensities under both regimes requires that $\tilde{\mathbf{x}}^{R}=\hat{\mathbf{x}}^{M}$ and thus $\hat{z}=\tilde{z}$. A contradiction. Q.E.D.

Since a decrease in factor $i$ intensity can only come about with a decrease in the relative cost of factor $i$, we have the following corollary, which we state without proof:

Corollary 2 If $\hat{z}<\tilde{z}$ then $\xi_{i}\left(\tilde{\mathbf{x}}^{M}\right) \geq \xi_{i}\left(\tilde{\mathbf{x}}^{R}\right) \Leftrightarrow \hat{w}_{i} / \hat{w}_{j} \geq \tilde{w}_{i} / \tilde{w}_{j}$. 
The next lemma states that an increase in the use of factor $i$ 's intensity in the manufacturing sector is associated with a lower return to that factor in equilibrium.

Lemma $4 \xi_{i}\left(\tilde{\mathbf{x}}^{M}\right) \leq \xi_{i}\left(\hat{\mathbf{x}}^{M}\right) \Leftrightarrow \tilde{w}_{i} \geq \hat{w}_{i}$.

Proof: Observe that $\hat{w}_{i}=F_{i}^{M}\left(\hat{\mathbf{x}}^{M}\right)$ and $\tilde{w}_{i}=F_{i}^{M}\left(\tilde{\mathbf{x}}^{M}\right)$. Therefore $\tilde{w}_{i} \geq \hat{w}_{i}$ is equivalent to $F_{i}^{M}\left(\tilde{\mathbf{x}}^{M}\right) \geq F_{i}^{M}\left(\hat{\mathbf{x}}^{M}\right)$. Because marginal product $F_{i}^{M}$ is decreasing in factor $i$ 's intensity, this is also equivalent to $\xi_{i}^{M}\left(\tilde{\mathbf{x}}^{M}\right) \leq$ $\xi_{i}^{M}\left(\hat{\mathbf{x}}^{M}\right)$.Q.E.D.

We can now prove Theorem 1.

Proof: From Lemma 3, we have $\xi_{i}\left(\tilde{\mathbf{x}}^{M}\right) \geq \xi_{i}\left(\tilde{\mathbf{x}}^{R}\right) \Leftrightarrow \xi_{i}\left(\tilde{\mathbf{x}}^{M}\right) \geq \xi_{i}\left(\hat{\mathbf{x}}^{M}\right)$. From Lemma 4 , the latter inequality is equivalent to $\hat{w}_{i} \geq \tilde{w}_{i}$. Q.E.D.

In order to illustrate the implication of this theorem, suppose that initially, access to the resource sector is open to all and that given the technologies, output prices and factor endowments, the equilibrium factor prices are such that the manufacturing sector uses labor more intensively than the resource sector. Then, as the introduction of a restricted access regime leads to a drop in the aggregate exploitation efforts in the resource sector, the reallocation of factors will lead both sectors to use capital more intensively than before and as a result, the wage rate will increase. It remains to be shown that the exploitation effort level is lower under RA than OA.

\subsection{Effective input efforts in the resource sector}

Recall that in order to derive Theorem 1, we have posited that the RA regime's effective effort level in the resource sector would be lower than under OA. This may appear like an obvious consequence of access restriction. However, given that one factor cost is lower under RA than OA, we cannot a priori rule out the possibility that the net effect will be such that the unit cost of input efforts $c^{R}(\mathbf{w})$ drops to level low enough under RA that the resource exploitation level is higher than under OA. In this section, we show that the unit cost of effective effort in the resource sector is indeed lower under RA than OA, but that it is still the case that $\hat{z}<\tilde{z}$.

We begin with the following proposition, which states that the unit cost of effort in the resource sector is (weakly) lower under RA than OA. 
Lemma $5 c^{R}(\hat{\mathbf{w}}) \leq c^{R}(\tilde{\mathbf{w}})$

Before demonstrating Lemma 5, let us introduce two figures. Figure 2 represents the resource sector only and identifies the OA equilibrium at the intersection between the unit effort $\operatorname{cost} c^{R}(\tilde{\mathbf{w}})$ and its average product value $p \phi(\tilde{z})$, as per (11). Keep in mind, however, that unit effort cost $c^{R}(\tilde{\mathbf{w}})$ is endogenous since the factor cost vector $\tilde{\mathbf{w}}$ is determined along with the manufacturing sector equilibrium conditions and factor clearing.

Making use of the dual approach, equilibrium factor costs can however be illustrated on a graph with the use of isocost curves $c^{M}(\mathbf{w})=1$ and $c^{R}(\mathbf{w})=p \phi(\tilde{z})$, as in Figure 3. Indeed, at intersection point $\tilde{\mathbf{w}}$, both sector's equilibrium conditions (6) and (11) are respected and the corresponding factor price vector is the equilibrium one. Note that vectors $\tilde{\mathbf{a}}^{M}$ and $\tilde{\mathbf{a}}^{R}$, respectively normal to isocost curves $c^{M}(\mathbf{w})=1$ and $c^{R}(\mathbf{w})=p \phi(\tilde{z})$, represent the input vectors per unit of manufactured output and resource effort respectively. ${ }^{6}$ Consequently, assuming that the isocost curve of the manufacturing sector crosses that of the resource sector from below, we have that the manufacturing sector is relatively factor- $i$ intensive at OA equilibrium point $\tilde{\mathbf{w}}$, which corresponds to a point above the diagonal line in Figure 1, such as $\tilde{\mathbf{x}}$. (The converse holds if the isocost curve of the manufacturing sector crosses from above.) Note that we consider throughout that production is diversified under both property regimes; this requires that the economy's total factor endowment $\overline{\mathbf{x}}$ vector falls within the diversification cone formed by the area between vectors $\tilde{\mathbf{a}}^{M}$ and $\tilde{\mathbf{a}}^{R}$ and with origin at point $\tilde{\mathbf{w}} .^{7}$

Proof: Lemma 5 is formally demonstrated in Appendix A. The following provides a graphical representation. Assume instead that $c^{R}(\hat{\mathbf{w}})>c^{R}(\tilde{\mathbf{w}})$. Then according to (11) and (10), we have $p f^{\prime}(\hat{z})>p \phi(\tilde{z})$ and thus $\hat{z}<\underline{z}<\tilde{z}$, where $\underline{z}$ is defined as $f^{\prime}(\underline{z})=\phi(\tilde{z})$ (see Figure 2). If the manufacturing sector is relatively factor- $i$ intensive in the OA equilibrium, curve $c^{M}(\mathbf{w})=1$ intersects curve $c^{R}(\mathbf{w})=p \phi(\tilde{z})$ from below (see Figure 3 ). Now with $c^{R}(\hat{\mathbf{w}})>$ $c^{R}(\tilde{\mathbf{w}})$, the resource sector's unit effort isocost curve under RA must be above that under OA; this is illustrated by the dotted curve in Figure 3. The new equilibrium at point $\mathbf{w}^{\prime}$ is characterized by a drop in the relative price of

\footnotetext{
${ }^{6}$ This is a consequence of Shephard's lemma which states that $\tilde{\mathbf{a}}^{S}=\left(c_{i}^{S}(\mathbf{w}), c_{j}^{S}(\mathbf{w})\right)$. See, for instance, chapter 3 of Woodland (1982).

${ }^{7}$ Note also that if the cost functions were to intersect at multiple points, only one is compatible with a specific total factor endowment.
} 


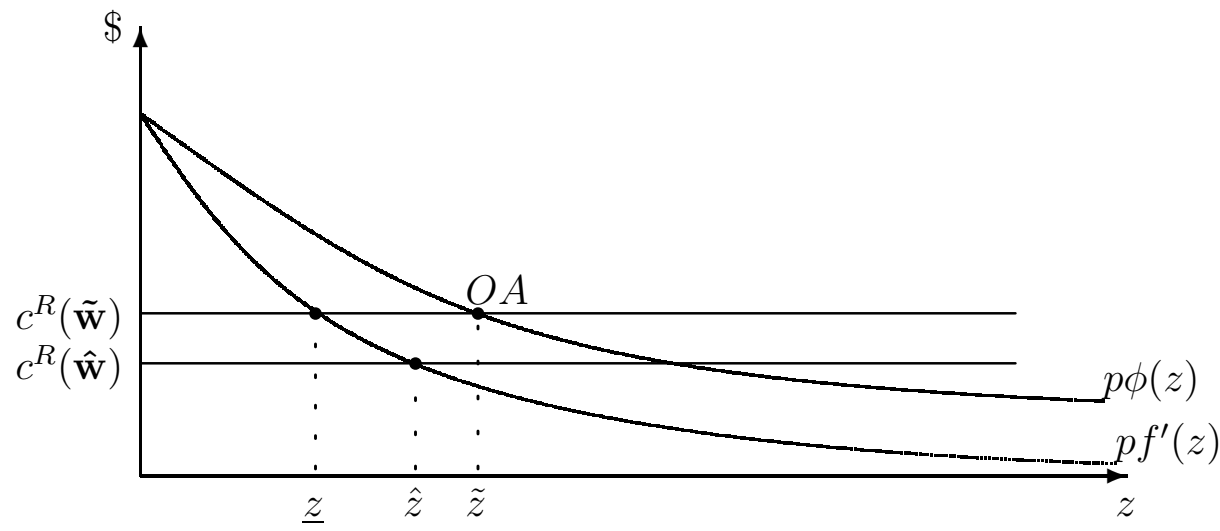

Figure 2: Resource sector, property regimes, and unit cost of effort

factor $i$ and thus a higher intensity in the use of factor $i$ in both sectors. As a consequence, the RA equilibrium falls in region $B$ of Figure 1, which corresponds to an increased use of both factors in the resource sector and therefore $\hat{z}>\tilde{z}$. A contradiction. Q.E.D.

Lemma 5 implies that the resource sector's RA regime isocost curve lies below that of the OA regime's. Consequently, the RA equilibrium wage vector $\hat{\mathbf{w}}$ must be located above the OA one $\tilde{\mathbf{w}}$ along the manufacturing sector's isocost curve, which is consistent with Theorem 1, i.e., in the case where the manufacturing sector is factor- $i$ intensive under OA, factor $i$ (factor $j$ ) is more (less) costly under RA than OA. It also implies the following:

\section{Lemma $6 \hat{z}<\tilde{z}$.}

Proof: A formal proof is provided in Appendix B. Graphically, it can be readily verified from Figure 1 that since the relative cost of factor $i$ increases under RA, a lower intensity of its use in both sectors requires that the RA equilibrium factor allocation must fall into area A, which is characterized by $\hat{\mathbf{x}} \ll \tilde{\mathbf{x}}$ and therefore $\hat{z}<\tilde{z}$. Q.E.D.

A natural question to ask at this point is what determines the intensity of factor use. The following section provides a clue to this question in terms of production technologies. 


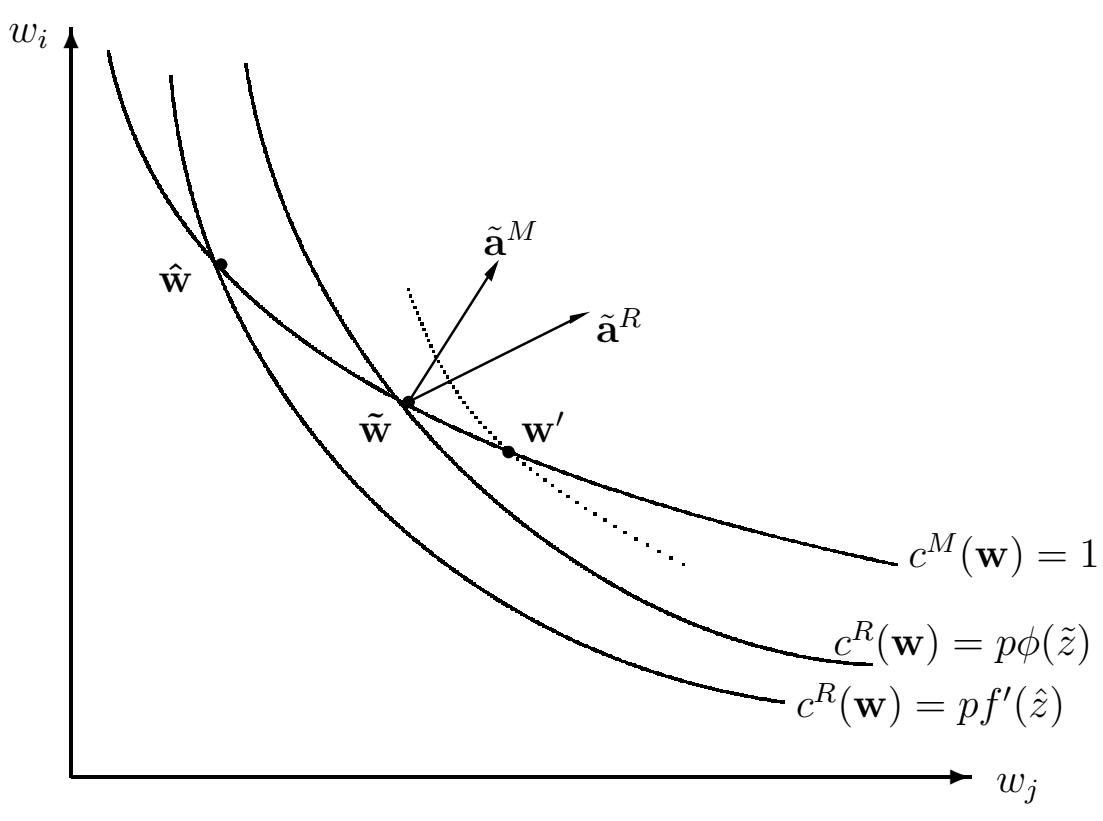

Figure 3: Isocost curves, property regime equilibria, and factor prices

\subsection{The role of output elasticities}

Since the relative factor intensities play such an important role in determining which factors gain and which lose from resource privatization, one may naturally ask what is it that determines relative factor intensities. According to the following proposition, relative factor intensities and output/effort elasticities to inputs are in fact one and the same.

The manufacturing output elasticity with respect to input $i$ is defined as follows:

$$
\epsilon_{i}^{M}\left(\mathbf{x}^{M}\right)=\frac{F_{i}^{M}\left(\mathbf{x}^{M}\right) x_{i}^{M}}{F^{M}\left(\mathbf{x}^{M}\right)}, i \in\{k, l\} .
$$

The output elasticity gives the percentage response of manufacturing output to a one percent increase in input $i$.

In the resource sector, we define the exploitation effort elasticity with 
respect to input $i$ as follows:

$$
\epsilon_{i}^{R}\left(\mathbf{x}^{R}\right)=\frac{F_{i}^{R}\left(\mathbf{x}^{R}\right) x_{i}^{R}}{F^{R}\left(\mathbf{x}^{R}\right)}, \quad i \in\{l, k\} .
$$

Proposition $2 \epsilon_{i}^{R}\left(\tilde{\mathbf{x}}^{R}\right) \geq \epsilon_{i}^{M}\left(\tilde{\mathbf{x}}^{M}\right) \Leftrightarrow \xi_{i}\left(\tilde{\mathbf{x}}^{R}\right) \geq \xi_{i}\left(\tilde{\mathbf{x}}^{M}\right)$.

Proof: By definition of the output/effort elasticities to inputs, we have $\tilde{x}_{i}^{S}=\epsilon_{i}^{S}\left(\tilde{\mathbf{x}}^{S}\right) F^{S}\left(\tilde{\mathbf{x}}^{S}\right) / F_{i}^{S}\left(\tilde{\mathbf{x}}^{S}\right)$ for all $S \in\{M, R\}$ and $i \in\{k, l\}$. Thus

$$
\xi_{i}\left(\tilde{\mathbf{x}}^{S}\right)=\frac{\epsilon_{i}^{S}\left(\tilde{\mathbf{x}}^{S}\right)}{\epsilon_{j}^{S}\left(\tilde{\mathbf{x}}^{S}\right)} \frac{F_{j}^{S}\left(\tilde{\mathbf{x}}^{S}\right)}{F_{i}^{S}\left(\tilde{\mathbf{x}}^{S}\right)} .
$$

Now from the equilibrium conditions (5) and (12), we have,

$$
\frac{F_{j}^{M}\left(\tilde{\mathbf{x}}^{M}\right)}{F_{i}^{M}\left(\tilde{\mathbf{x}}^{M}\right)}=\frac{\tilde{w}_{i}}{\tilde{w}_{j}}=\frac{F_{j}^{R}\left(\tilde{\mathbf{x}}^{R}\right)}{F_{i}^{R}\left(\tilde{\mathbf{x}}^{R}\right)} .
$$

Therefore $\xi_{i}\left(\tilde{\mathbf{x}}^{R}\right) \geq \xi_{i}\left(\tilde{\mathbf{x}}^{M}\right)$, if and only if,

$$
\frac{\epsilon_{i}^{R}\left(\tilde{\mathbf{x}}^{R}\right)}{\epsilon_{j}^{R}\left(\tilde{\mathbf{x}}^{R}\right)} \geq \frac{\epsilon_{i}^{M}\left(\tilde{\mathbf{x}}^{M}\right)}{\epsilon_{j}^{M}\left(\tilde{\mathbf{x}}^{R}\right)} .
$$

Using the fact that for linear homogeneous functions $F^{S}$, the output/effort elasticities to inputs must satisfy $\epsilon_{i}^{S}\left(\tilde{\mathbf{x}}^{S}\right)+\epsilon_{j}^{S}\left(\tilde{\mathbf{x}}^{S}\right)=1, S \in\{M, R\}$, inequality (15) is equivalent to $\epsilon_{i}^{R}\left(\tilde{\mathbf{x}}^{R}\right) \geq \epsilon_{i}^{M}\left(\tilde{\mathbf{x}}^{M}\right)$. Q.E.D.

Proposition 2 implies that under an open access equilibrium, the manufacturing sector is labor intensive relative to the resource sector if, and only if, the elasticity of output to capital in the manufacturing sector is lower than the elasticity of effort to capital in the resource sector. Whether this the case or not in practice will depend on the context. This includes factors such as the type of natural resource and the available technologies.

\section{Conclusion}

We have seen that when both labor and capital are mobile between sectors, as one would expect in the long run, the creation of property rights in the resource sector will contribute to raise wages if, and only if, the manufacturing 
sector uses labor relatively intensively. This result contrasts with previous ones in the literature which suggested that resource privatization would necessarily contribute to lower wages, a result which is now shown to rest on the assumption that labor is the sole mobile factor, usually considered as a short-run view. Our analysis introduced a dual approach to equilibrium in the production sector in order to compare two property regimes.

One may envision extending the analysis with the introduction of transaction costs associated with the creation of property rights. Given that the enforcement of property rights in the natural resource sector are notoriously difficulty to enforce, it may be of interest to explicitly introduce the use of enforcement labor and capital into the analysis. The basic model may also lend itself well to an analysis of the role of labor wages and the returns to capital in explaining the occurrence of conflict in the presence of natural resources.

Another avenue of research would consist in the introduction of a more explicit role for trade by relaxing the small open economy assumption.

\section{A Proof that $c^{R}(\hat{\mathbf{w}}) \leq c^{R}(\tilde{\mathbf{w}})$}

Recall that equilibrium conditions for factor payments must respect condition (6) and either of (11) or (10). Let us express those by the following set of two equations, where parameter $\alpha$ is either equal to $p \phi(\tilde{z})$ or $p f^{\prime}(\hat{z})$ :

$$
\begin{gathered}
c^{M}\left(w_{i}, w_{j}\right)-1=0, \\
c^{R}\left(w_{i}, w_{j}\right)-\alpha=0 .
\end{gathered}
$$

Differentiating these two expressions with respect to parameter $\alpha$ and making use of Cramer's rule yields:

$$
\begin{aligned}
\frac{\partial w_{i}}{\partial \alpha} & =\frac{-c_{j}^{M}}{c_{i}^{M} c_{j}^{R}-c_{i}^{R} c_{j}^{M}}, \\
\frac{\partial w_{j}}{\partial \alpha} & =\frac{c_{i}^{M}}{c_{i}^{M} c_{j}^{R}-c_{i}^{R} c_{j}^{M}} .
\end{aligned}
$$

Now according to Shephard's lemma, $c_{i}^{S}$ denotes the quantity of factor $i$ used in sector $S$ per unit of output, i.e., $y^{S} c_{i}^{S}=x_{i}^{S}, S \in\{M, R\}$, and similarly for 
factor $j$. Inserting this into the above two equations yields:

$$
\begin{aligned}
\frac{\partial w_{i}}{\partial \alpha} & =\frac{-y^{R} x_{j}^{M}}{x_{i}^{M} x_{j}^{R}-x_{i}^{R} x_{j}^{M}}, \\
\frac{\partial w_{j}}{\partial \alpha} & =\frac{y^{R} x_{i}^{M}}{x_{i}^{M} x_{j}^{R}-x_{i}^{R} x_{j}^{M}} .
\end{aligned}
$$

We consequently have:

$$
\begin{aligned}
& \frac{\partial w_{i}}{\partial \alpha}<0 \text { iff } \xi_{i}\left(\mathbf{x}^{M}\right)>\xi_{i}\left(\mathbf{x}^{R}\right) \\
& \frac{\partial w_{j}}{\partial \alpha}>0 \text { iff } \xi_{i}\left(\mathbf{x}^{M}\right)>\xi_{i}\left(\mathbf{x}^{R}\right) .
\end{aligned}
$$

Without loss of generality, we posit that $\xi_{i}\left(\mathbf{x}^{M}\right)>\xi_{i}\left(\mathbf{x}^{R}\right) .{ }^{8}$ The above therefore implies that an increase in $\alpha$ leads to a decrease in $w_{i} / w_{j}$.

Assume now that $c^{R}(\hat{w})>c^{R}(\tilde{w})$. This implies that $\alpha$ must take on a larger value under RA than $\mathrm{OA}$ and thus, according to the above result, $\hat{w}_{i} / \hat{w}_{j}<\tilde{w}_{i} / \tilde{w}_{j}$. But $c^{R}(\hat{w})>c^{R}(\tilde{w})$ also implies that $\hat{z}<\tilde{z}$, as can be readily seen from Figure 2. Now according to Corollary $2, \xi_{i}\left(\mathbf{x}^{M}\right) \geq \xi_{i}\left(\mathbf{x}^{R}\right)$ implies $\hat{w}_{i} / \hat{w}_{j} \geq \tilde{w}_{i} / \tilde{w}_{j}$ when $\hat{z}<\tilde{z}$. A contradiction. Q.E.D.

\section{B Proof that $\hat{z}<\tilde{z}$}

Assume to the contrary that $\hat{z} \geq \tilde{z}$. Then, it must be the case that $c^{R}(\hat{w})<$ $c^{R}(\tilde{w})$. In line with the analysis of Appendix A above, this calls for a lower value of $\alpha$ under RA as compared to OA and therefore $\hat{w}_{i} / \hat{w}_{j}>\tilde{w}_{i} / \tilde{w}_{j}$. Consequently, factor $i$ is used less intensively under RA than OA and, as can be readily seen in Figure 1 , this requires $\hat{\mathbf{x}}^{R} \ll \tilde{\mathbf{x}}^{R}$ and thus $\hat{z}<\tilde{z}$. A contradiction. Q.E.D.

\section{References}

[1] Ambec, Stefan and Louis Hotte (2006) 'On the redistributive impact of privatizing a resource under imperfect enforcement.' Environment and Development Economics 11, 677-696.

\footnotetext{
${ }^{8}$ Note that the problem is undefined for $\xi_{i}\left(\mathbf{x}^{M}\right)=\xi_{i}\left(\mathbf{x}^{R}\right)$.
} 
[2] Anderson, Terry L. and Peter J. Hill (1983) 'Privatizing the commons: An improvement?' Southern Economic Journal 50, 38-45.

[3] Baland, Jean-Marie and Patrick Francois (2005) 'Commons as insurance and the welfare impact of privatization.' Journal of Public Economics 89, 211-231.

[4] Brander, James A. and M. Scott Taylor (1997) 'International trade and open access renewable resources: The small open economy case.' Canadian Journal of Economics 30, 526-552.

[5] Brito, Dagobert L., Michael D. Intriligator and Eytan Sheshinski (1997) 'Privatization and the distribution of income in the commons.' Journal of Public Economics 64, 181-205.

[6] Brooks, Michael A., and Ben J. Heijdra (1990) 'Rent-seeking and the privatization of the commons.' European Journal of Political Economy $6,41-59$.

[7] Cheung, Steven N. S. (1970) 'The structure of a contract and the theory of a non-exclusive resource.' Journal of Law and Economics 13, 45-70.

[8] Chichilnisky, Graciela (1994) 'North-south trade and the global environment.' The American Economic Review 84, 851-874.

[9] de Meza, David and J.R. Gould (1987) 'Free access versus private property in a resource: Income distributions compared.' Journal of Political Economy 95, 1317-1325.

[10] Gordon, H. Scott (1954) 'The economic theory of a common-property resource: The fishery.' Journal of Political Economy 62, 124-142.

[11] Hotte, Louis, Ngo Van Long and Huilan Tian (2000) 'International trade with endogenous enforcement of property rights.' Journal of Development Economics 62, 25-54.

[12] Jones, R. W. (1971) 'A three factor model in theory, trade and history.' In Trade, Balance of Payments, and Growth, ed. J. Bhagwati, R.W. Jones, R. Mundell, and J. Vanek (Amsterdam: North-Holland).

[13] Karp, Larry (2005) 'Property rights, mobile capital, and comparative advantage.' Journal of Development Economics 77, 367-387. 
[14] Mayer, Wolfgang (1974) 'Short-run and long-run equilibrium for a small open economy.' Journal of Political Economy 82, 955-967.

[15] Mussa, Michael (1974) 'Tariffs and the distribution of income: The importance of factor specificity, substitutability, and intensity in the short and long run.' Journal of Political Economy 82, 1191-1204.

[16] Samuelson, Paul A. (1974) 'Is the rent-collector worthy of his full hire?' Eastern Economic Journal 1, 7-10.

[17] Weitzman, Martin L. (1974) 'Free access vs private ownership as alternative systems for managing common property.' Journal of Economic Theory 8, 225-234.

[18] Woodland, Alan D. (1982) International Trade and Resource Allocation (Amsterdam: North-Holland Publishing Company). 